Research Article

\title{
Research on Damage Characteristics of Brick Masonry under Explosion Load
}

\author{
Jifeng Wei $(\mathbb{D}$, Zhixin Du, Yonghui Zheng, and Oundavong Ounhueane \\ State Key Laboratory of Explosion Science and Technology, Beijing Institute of Technology, Beijing 100081, China \\ Correspondence should be addressed to Jifeng Wei; weijifeng@bit.edu.cn
}

Received 3 March 2021; Revised 16 June 2021; Accepted 23 July 2021; Published 26 August 2021

Academic Editor: Bangbiao Wu

Copyright (c) 2021 Jifeng Wei et al. This is an open access article distributed under the Creative Commons Attribution License, which permits unrestricted use, distribution, and reproduction in any medium, provided the original work is properly cited.

\begin{abstract}
As the main structural component of partition wall or load-bearing wall, brick masonry has been widely used in construction engineering. However, brick and mortar are all brittle materials prone to crack. Nowadays, fireworks, gas stoves, high-pressure vessels, and other military explosives may explode to damage nearby structures. Many explosion casualties had shown that the load-bearing capacity of brick masonry decreased dramatically and cracks or fragments appeared. Previous studies mainly focused on noncontact explosion in which shock wave is the main damage element. In fact, the response and damage effect of brick masonry wall under contact explosion are more complex, which attracts more attention now. In order to explore the damage characteristics of brick masonry under explosion load, a series of simulations and verification experiments are conducted. RHT and MO granular material models are introduced to describe the behaviour of brick and masonry, respectively, in simulation. The combination effect of front compressive wave and back tensile wave are main factors influencing the breakage of masonry wall. The experimental results are well in accordance with the simulation results. The front cross section dimension of crater is closely related to the radius of spherical explosive charge. A power function predictive model is developed to express the relationship between the radius of hole and the radius of explosive. Furthermore, with increasing the quantity of explosive charge, the number and ejection velocity of fragments are all increased. The relationship between maximum ejection velocity and the quantity of explosive also can be expressed as a power function model.
\end{abstract}

\section{Introduction}

Brick masonry is a composite structure which consists of brick, mortar, and brick-mortar interfaces. With lots of advantages of easy availability, good durability, low-cost building material, and sound and insulation properties, it has been widely used in civil constructions. However, masonry materials (sintered bricks and mortar) are brittle materials with low ductility which is easy to crack under severe impact or explosion [1-3]. Failure of a masonry wall is likely to be sudden and severe that poses significant debris hazard to building occupants when subjected to blast loads. According to the analysis of human casualties and property losses in explosion accidents, it had been found that the fragmentation of brick masonry also can cause damage to whether human or surrounding devices except high overpressure [4-6].
Previous research studies had paid more attention to experiments. Varma et al. [7] tested on several masonry panels with different thickness subjected to near-field and far-field explosions. Gabrielsen et al. [8] investigated experimentally the response of building walls to blast loading from large nuclear weapons. Davidson et al. [9] conducted three explosive tests that involved a sprayed-on polymer to increase blast resistance of unreinforced concrete masonry walls. Dennis et al. [10] conducted both five dynamic experiments to analyse the response and failure of one-way 1/4-scale reinforced masonry walls to blast loads. Ahmad et al. [11] carried out six tests to study the resistance of brick masonry wall exposed to varying blast load at different scaled distances. Keys et al. [12] carried out two experimental trials to obtain a baseline set of results for the breakage mechanisms and debris distribution and developed a new method to predict the spatial debris distribution. Norén-Cosgriff 
et al. [13] observed the onset of cracking of building and measured air blast overpressure and vibrations on the ground surface.

By far many simulations on damage behaviours and phenomena of brick masonry under dynamic loads had been done. Zhou et al. [14] simulated the damage and fragmentation of a typical masonry wall under blast loading at different scaled distances. Keys et al. [15] used applied element method to calculate the breakage and debris distribution of masonry subjected to long duration blast loading. Shadlou et al. [16] presented a brief discussion about the main challenges on modelling the reinforced concrete frames, masonry infills, and interaction between them for structures located in seismic zones. Some scholars [17-20] used brick masonry discrete model to explore the details of damage development process of the masonry and the damage phenomenon at the interface between the brick and the mortar. However, this method would consume lots of central processing unit (CPU) and memory resources of computer during calculations [21]. Other scholars [22-26] adopted equivalent homogenized material model to characterize the overall properties of masonry walls.

By now, few researches had been done to study the response of brick masonry under contact explosion loads. In the present study, a series of numerical simulations and experiments are carried out to study the structural response and damage characteristics of brick masonry wall under contact explosion loads. Different explosive charges are deployed in the same contact position to compare the difference among them. The relationship between the dimension of crater and the radius of explosive is obtained. The damage mechanism of brick masonry under explosion load is analysed. Furthermore, the fragmentation and maximum ejection velocities of brick masonry under different conditions are studied.

\section{Computational Model}

2.1. Physical Model and Algorithm. The brick masonry wall is composed of mortar and regularly arranged bricks. A separate model is used to establish the brick wall; that is, the brick and mortar are used as independent components. This type of modelling method is intuitive and can accurately simulate the bond between the mortar and the brick. Here, the size of brick is $240 \mathrm{~mm}$ (length) $\times 115 \mathrm{~mm}$ (width) $\times$ $53 \mathrm{~mm}$ (thick). 6 pieces are placed in the length direction of the wall ( $X$-direction), 22 pieces are placed in the height direction ( $Y$-direction), 2 pieces are placed in the thickness direction ( $Z$-direction), and the thickness of mortar is $10 \mathrm{~mm}$. So, the total size of brick wall is $1250 \mathrm{~mm} \times 1490 \mathrm{~mm} \times 240 \mathrm{~mm}$.

Both brick and mortar are all divided with Lagrange cells. In Lagrange algorithm, the material is attached to the grid to trace the flow of each mass point. The grid and the material are deformed together and the coordinates move with the material, which is one of the most widely used methods to solve the explosion and impact problems. The boundaries of brick wall are all imposed six degrees of freedom constraints, as shown in Figure 1. The spherical composition 4 (C4) explosive is established by Smoothed Particle Hydrodynamics (SPH). As a meshless discretization method, the main advantage of SPH method has advantage to avoid severe problems associated with mesh tangling and distortion which usually occur in Lagrangian analysis involving large deformation impact and explosive loading events. The explosive is attached to the geometric centre of front surface of brick masonry wall and is detonated from the centre of itself. In order to obtain the pressure on the wall and trace the damage zone, a series of gauge points are set along the horizontal and vertical directions of front and back surfaces. The established simulation model is shown in Figure 2.

2.2. Material Model and Parameters. There are two materials in this study, C4 explosives (main charge) and brick masonry (including brick and mortar). The material models and parameters used in these materials are described, respectively.

2.2.1. C4 Explosive. As a plastic explosive, $\mathrm{C} 4$ is composed of RDX (hexogen), plastic binder, and plasticizer. RDX is the main component of it, about $91 \%$. It is easy to be kneaded into various shapes at will which is often used in breaching obstacles or demolition of large structures. Although this kind of explosive is powerful, it is very safe to use. Even if it is shot directly, it is hard to explode. It can only be detonated with a detonator.

The equation of state (EOS) of detonation products is essential for describing the detonation properties of explosives, and it is the core parameter in simulations of detonation process of explosives. In AUTODYN numerical simulation program, there are three EOS suitable for explosives: Becker-Kistiakowsky-Wilson (BKW) EOS, Jones-Wilkins-Lee (JWL) EOS, and Lee-Tarver EOS. Among them, JWL EOS can accurately describe the characteristics of the detonation product volume, pressure, temperature, and energy during the detonation process [27-29]. The main parameters of JWL EOS for C4 explosive are shown in Table 1 . Besides, its loading density $\rho_{e}$, detonation velocity $D_{e}$, and CJ pressure $P_{C J}$ are $1.60 \mathrm{~g} \cdot \mathrm{cm}^{-3}$, $8193 \mathrm{~m} \cdot \mathrm{s}^{-1}$, and $28 \mathrm{GPa}$, respectively.

The expression of JWL EOS is as follows:

$$
P=A\left(1-\frac{\omega}{R_{1} V}\right) e^{-R_{1} V}+B\left(1-\frac{\omega}{R_{2} V}\right) e^{-R_{2} V}+\frac{\omega E_{0}}{V},
$$

where $P$ is the pressure, $E_{0}$ is the initial specific energy, $V$ is the relative volume of the detonation product, and $A, B, R_{1}$, $R_{2}$, and $\omega$ are constants. The parameters $A$ and $B$ have dimensions of pressure, while $R_{1}, R_{2}$, and $\omega$ are dimensionless.

2.2.2. Brick Masonry. Brick masonry is a solid entity composed of many blocks that are bonded by mortar as a whole. RHT strength and failure model is chosen to describe the behaviour of brick material, while Mo granular strength model is used to describe the behaviour of mortar material. 


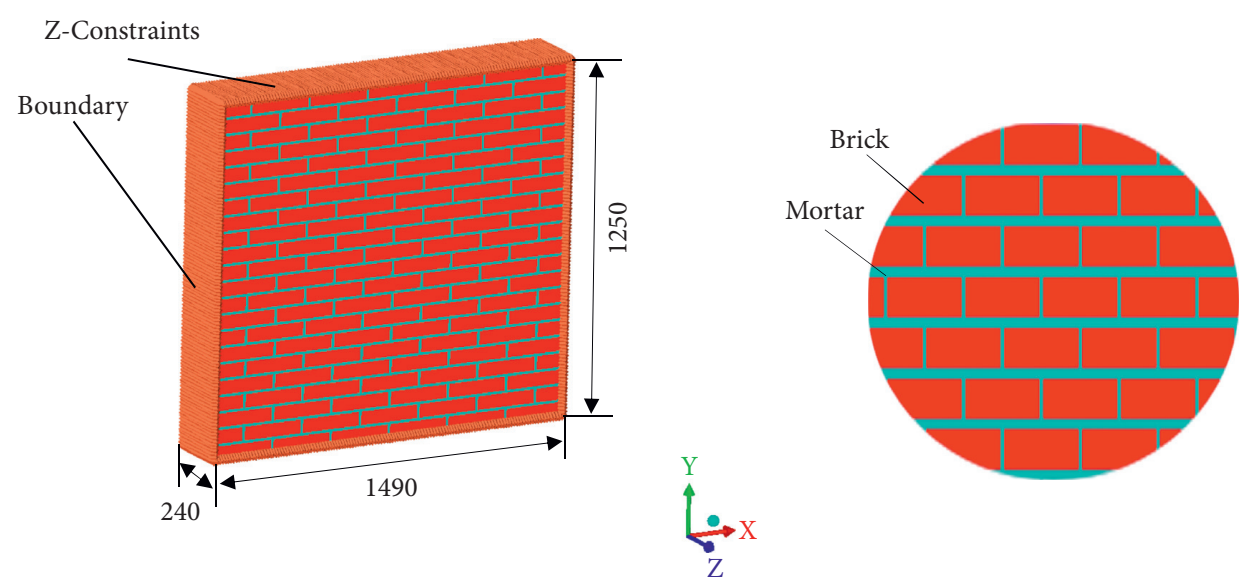

FIGURE 1: Finite element model of brick masonry.
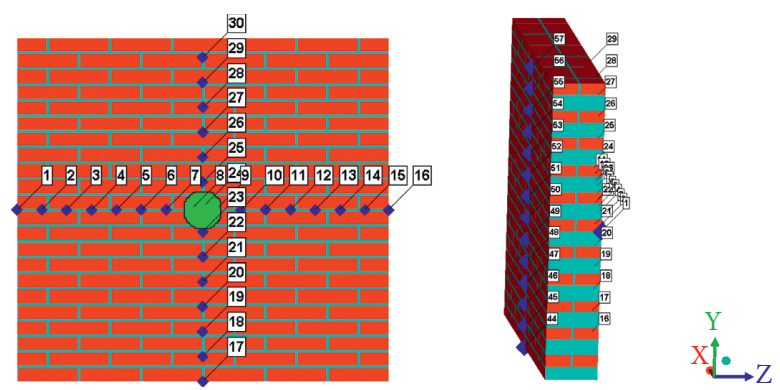

Figure 2: The layout of gauge points.

TABLE 1: Parameters of JWL EOS for C4 explosive.

\begin{tabular}{lccccccccc}
\hline Parameter & $A(\mathrm{GPa})$ & $B(\mathrm{GPa})$ & $R_{1}$ & $R_{2}$ & $\omega$ & $E_{0}\left(\mathrm{~J} \cdot \mathrm{m}^{-3}\right)$ & $\rho_{e}\left(\mathrm{~g} \cdot \mathrm{cm}^{-3}\right)$ & $D_{e}\left(\mathrm{~m} \cdot \mathrm{s}^{-1}\right)$ & $P_{C J}(\mathrm{GPa})$ \\
\hline Value & 609.77 & 12.95 & 4.5 & 1.4 & 0.25 & $9.0 \times 10^{9}$ & 1.6 & 8193 & 28 \\
\hline
\end{tabular}

RHT model, first proposed by Riedel, Hiemaier, and Thoma, has developed and been widely used in the numerical simulation of explosion shock and other fields. This model is expressed in terms of three stress limit surfaces, namely, initial elastic yield surface, failure surface, and residual strength surface $[30,31]$. While the surfaces account for reduction in strength along different meridians as well as strain rate effects, the static compressive meridian surfaces are depicted in Figure 3. The failure surface is formed from material parameters including compressive, tensile, and shear strength of the brick. The model is elastic until the stress reaches the initial yield surface, beyond which plastic strains evolve. When the stress reaches the failure surface, a parameterized damage model governs the evolution of damage, driven by plastic strain, which in turn represents the post-failure stress limit surface by interpolating between failure surface and residual friction surface. There are three stages of linear strengthening and damage softening, as shown in Figure 3.

The failure surface $Y_{\text {fail }}^{*}$ is expressed as a function of the normalized pressure $p$, the Lode angle $\theta$, and strain rate $\dot{\varepsilon}$ :

$$
Y_{\text {fail }}^{*}=Y_{\mathrm{TXC}}^{*}(p) \cdot R_{3}(\theta) \cdot F_{\mathrm{RATE}}(\dot{\varepsilon}),
$$

where $Y_{\text {TXC }}^{*}(p)$ represents the compression meridian intensity, $R_{3}(\theta)$ is introduced to describe the reduced strength on shear and tensile meridian, and $F_{\mathrm{RATE}}(\dot{\varepsilon})$ represents the dynamic increase factor (DIF) as a function of the strain rate.

The moving elastic limit surface $Y_{\text {ela }}^{*}$ can be described as follows:

$$
Y_{\text {ela }}^{*}=Y_{\text {fail }}^{*} F_{\mathrm{CAP}}(p),
$$

where $F_{\mathrm{CAP}}(p)$ is a function that limits the elastic deviatoric stresses under hydrostatic compression.

In order to describe the strength of the completely crushed material, a residual failure surface $Y_{\text {res }}^{*}$ is defined as

$$
Y_{\text {res }}^{*}=B \times\left(p^{*}\right)^{M},
$$

where $B$ is the residual failure surface constant, $p^{*}$ is the normalized hydrostatic pressure, and $M$ represents the residual failure surface exponent.

The main parameters of brick material are shown in Table 2 . 


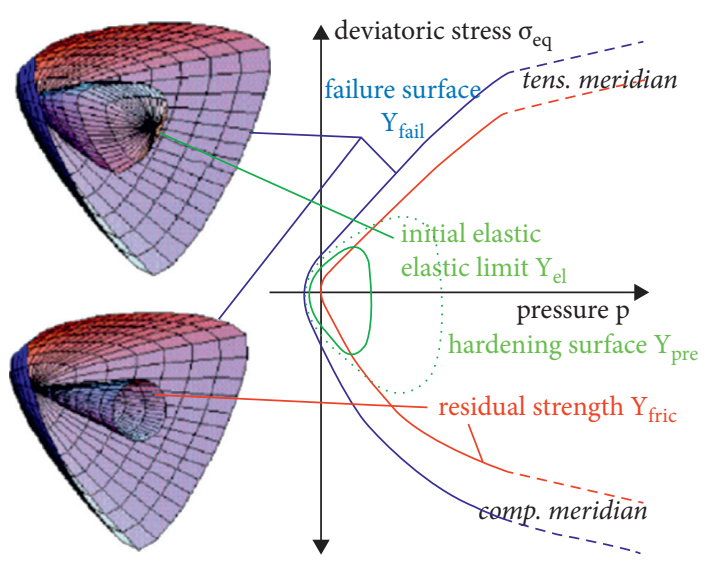

FIgURE 3: The reference spatial distribution and meridian of RHT constitutive elastic limit surface, failure surface, and residual strength surface.

TABLE 2: Main parameters of brick material.

\begin{tabular}{lcccccc}
\hline Density $\left(\mathrm{g} \cdot \mathrm{cm}^{-3}\right)$ & $\begin{array}{c}\text { Compressive strength } \\
(\mathrm{MPa})\end{array}$ & $\begin{array}{c}\text { Volume modulus } \\
(\mathrm{GPa})\end{array}$ & $\begin{array}{c}\text { Shear modulus } \\
(\mathrm{GPa})\end{array}$ & $\begin{array}{c}\text { Damage } \\
\text { constant } D_{1}\end{array}$ & $\begin{array}{c}\text { Damage } \\
\text { constant } D_{2}\end{array}$ & $\begin{array}{c}\text { Tensile strength } \\
(\mathrm{MPa})\end{array}$ \\
\hline 2.25 & 2.6 & 11.0 & 4.4 & 0.014 & 1.0 & 6.0 \\
\hline
\end{tabular}

MO granular continuum model, proposed by Moxnes et al. in 1999, is an extension of the Drucker-Prager model that considers the effects associated with granular materials $[32,33]$. The model uses a hydrostatic compaction curve as a function of the density, a model for the yield stress as a function of pressure and elastic modulus as a function of density. The model does not include any strain rate dependency of yield stress. The parameters are constructed by using a quasistatic unilateral compression test and validated by using a high-speed piston (up to $300 \mathrm{~m} / \mathrm{s}$ ) impacting a granular pyrotechnic bed. The yield stress can be described as

$$
\sigma_{y}=\sigma_{p}+\sigma_{\rho} \cdot F
$$

where $\sigma_{y}, \sigma_{p}$, and $\sigma_{\rho}$ denote the total yield stress, the pressure yield stress, and the density yield stress, respectively, and $F$ is initially supplied by the user as the initial fraction of yield. Failure occurs if the von Mises stress is greater than both the total yield stress $\sigma_{y}$ and $F_{S} P$, where $F_{S}$ is the user defined variable slope and $P$ is pressure. The material parameters of mortar are shown in Table 3.

\section{Results and Discussion}

3.1. Analysis of the Fracture Process of Brick Masonry. When an explosive is detonated, the expansion of the hot gases at extremely high pressures causes a shock wave to form, moving outward at high velocity. Nearby structures will suffer some degree of damage from it. If the explosive is put on the surface of the structure to explode, higher-pressure, shorter load durations will be obtained. At this time, a part of the shock wave will penetrate into contacted brick masonry. This part of shock wave is so called transmission shock wave. It will also be affected by a reverse incoming sparse wave. This reflected wave will form a reflected shock wave load. The propagation of shock waves not only causes dynamic stress to the medium, but also causes the movement, deformation, or destruction of the medium. Shock wave cannot be supplemented with energy during its propagation process, so it will gradually weaken and finally disappear.

When the brick masonry is impacted by the explosion of $2.0 \mathrm{~kg} \mathrm{C} 4$ spherical charge, the zone suffered from severe impact is damaged to form a crater. Figure 4 shows successive frames of fracture development after explosion on the front surface of brick masonry. It can be seen that the dimensions of crater increase gradually; finally, a big hole is formed.

The stress contours of brick masonry under explosion loads are shown in Figure 5(a). The closer to the centre the element is, the larger the stress is. Accordingly, the larger the strain gets. When the strains of elements are up to failure strain, the elements will be eroded, such as gauge $\# 8$, gauge $\# 9$, and gauge \#23 on the front surface close to the centre of brick masonry (in Figure 5(b)). The strains of other gauges are lower than failure strain, so they do not fail. The zone with a large number of continuous eroded elements is called a crater. The more the effective strains of elements reach failure strain, the larger the carter is. Figure 5(c) shows that the compression behaviour of different gauges. When the value of compression is below zero, the gauges suffer from the effect of tensile stress. When the crater breaks, a few fragments will be extruded from it. The maximum ejection velocity is about $16.2 \mathrm{~m} \cdot \mathrm{s}^{-1}$, as shown in Figure 5(d).

Figure 6 presents the dimensions change of damage zone on the front surface when brick masonry wall is damaged by $2.0 \mathrm{~kg}$ C4 spherical charge. With the increase of time, three dimensions become larger and larger. The $240 \mathrm{~mm}$ thickness 
TABLE 3: Main parameters of mortar material.

\begin{tabular}{lcccc}
\hline Density $\left(\mathrm{g} \cdot \mathrm{cm}^{-3}\right)$ & Poisson's coefficient & Volume modulus $(\mathrm{GPa})$ & Shear strength residual coefficient $(\mathrm{GPa})$ & $\begin{array}{c}\text { Failure principal } \\
\text { tensile stress }(\mathrm{MPa})\end{array}$ \\
\hline 1.7 & 0.10 & 5.9 & 2.2 & 1.0 \\
\hline
\end{tabular}

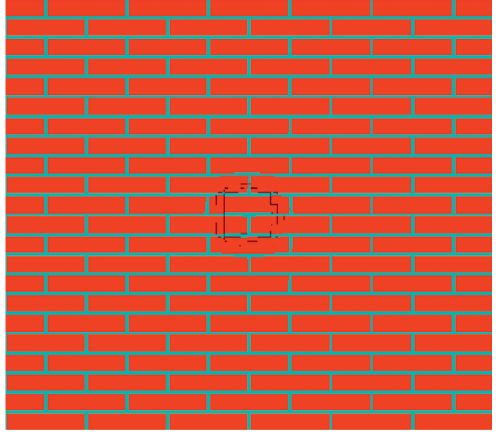

(a)

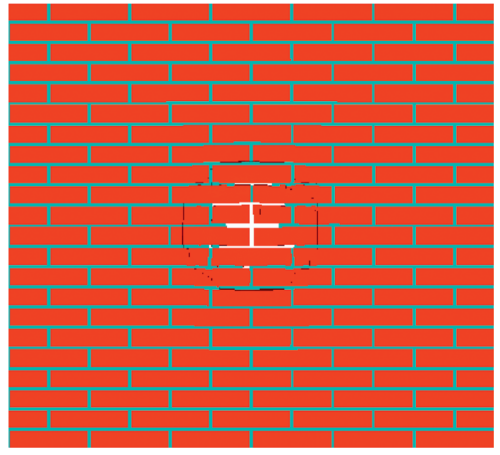

(d)

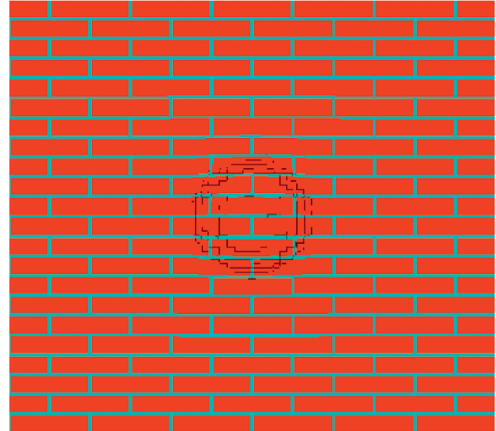

(b)

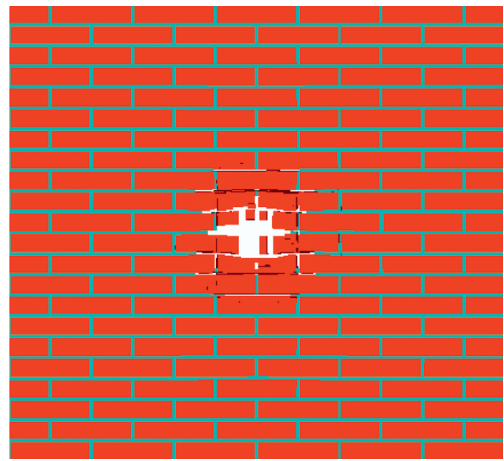

(e)

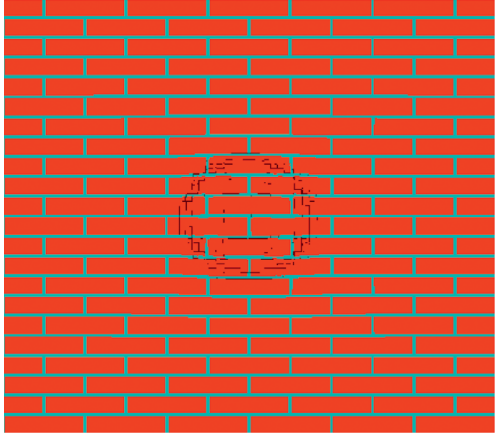

(c)

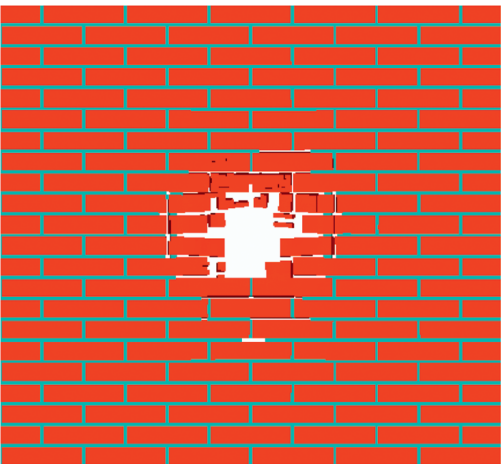

(f)

Figure 4: The fracture development of brick masonry by $2.0 \mathrm{~kg} \mathrm{C} 4$ explosive. (a) $0.1 \mathrm{~ms}$. (b) $0.5 \mathrm{~ms}$. (c) $1.0 \mathrm{~ms}$. (d) $2.0 \mathrm{~ms}$. (e) $4.0 \mathrm{~ms}$. (f) $6.0 \mathrm{~ms}$.

wall cracks at about $2.0 \mathrm{~ms}$ while the crater reaches its maximum cross section at about $5 \mathrm{~ms}$. Before the crater breaks, it has reached the maximum cross section surface, beyond $400 \mathrm{~mm}$. The growth rates of $X$ and $Y$ dimensions are almost the same, which are larger than that of $Z$ dimension. So, the shape of cross section of crater is close to be circular.

\subsection{Damage Zone of Brick Masonry under Different Charges.} In order to study the damage characteristics of the brick masonry under different explosion loads, five C4 spherical charges, $0.5 \mathrm{~kg}, 1.0 \mathrm{~kg}, 2.0 \mathrm{~kg}$, and $4.0 \mathrm{~kg}$, are designed. The radii of these charges are $42.10 \mathrm{~mm}, 53.04 \mathrm{~mm}, 66.82 \mathrm{~mm}$, and $84.19 \mathrm{~mm}$, respectively. These charges are all placed on the centre of front surface of brick masonry wall to explode.

Figure 7 gives damaged pattern of the back of brick masonry wall subjected to different explosion loads. As we know, shock wave will be produced when explosive is detonated and then turns to compression wave in brick masonry. When stress wave transmits to the back free surface of brick masonry, a reverse tensile wave is inevitably formed to stretch the back to go farther. When the quantity of charge is smaller, such as $0.5 \mathrm{~kg}$, a small crater is found on the front face just at the contact position. Seen from the back surface of the wall, there is a small hole and few fragments are extruded. When the quantity of charge increases to $1.0 \mathrm{~kg}$, a larger crater is formed on the front. Viewing from the back, the mortar in the centre is extended to form a larger hole and a few fragments are ejected. At the same time, it can be found that left and right sides of masonry wall are slightly affected by such a high explosion. That may be due to the bond strength of transverse mortar layer being lower than that of longitudinal brick-mortar interaction. If $2.0 \mathrm{~kg} \mathrm{ex}-$ plosive charge is used, deeper crater appears with more distinct bulge on the back. The crater breaks to form more fragments and two sides of masonry wall are heavily affected along transverse mortar layers. When the charge reaches $4.0 \mathrm{~kg}$, an even larger crater appears. The sizes of back fracture zone and hole are all larger than above results.

Next, two experiments were conducted to investigate the damage characteristics of masonry wall. $1.0 \mathrm{~kg}$ and $2.0 \mathrm{~kg}$ spherical explosive charge were chosen to be detonated on the surface of masonry wall. Crater holes are formed under such two equivalent explosives, as shown in Figure 8. 

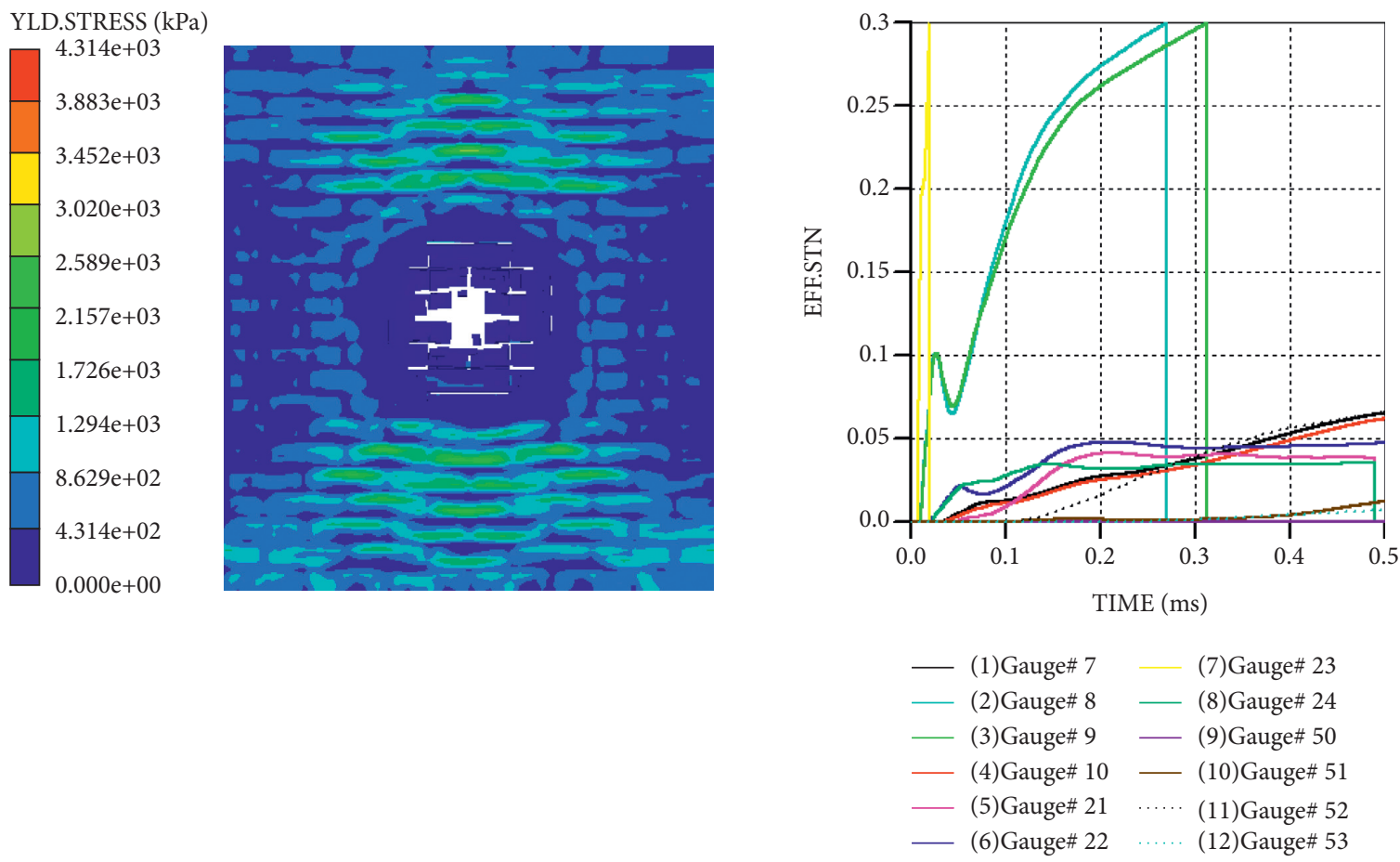

(a)
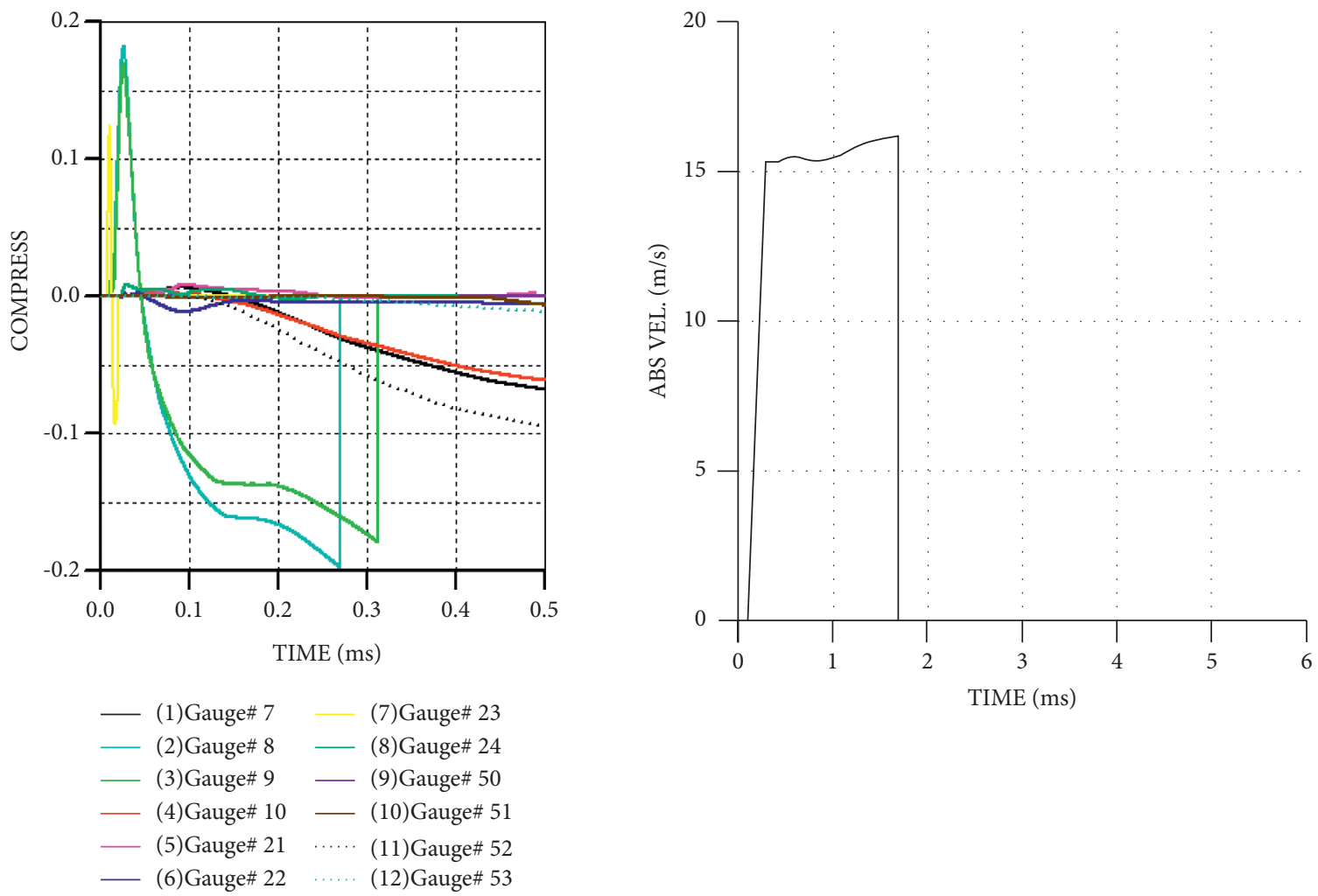

(c)

(d)

Figure 5: Simulation results of $2.0 \mathrm{~kg} \mathrm{C4}$ explosion load. (a) Contour of stress distribution. (b) Effective strains of gauges. (c) Compression behaviour of gauges. (d) Ejection velocity of fragments. 


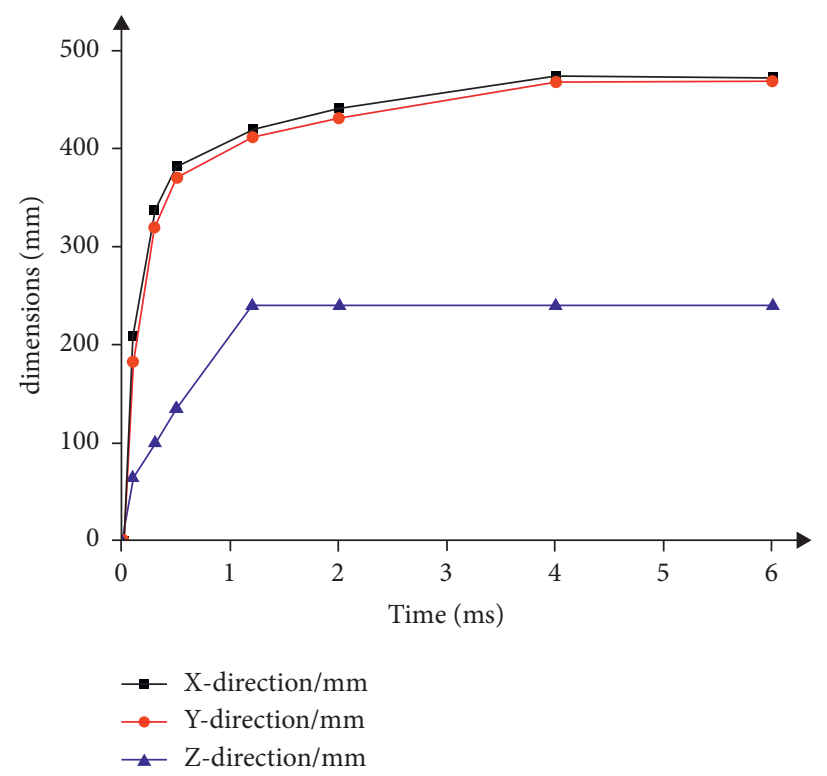

FIgURE 6: The dimensions in three directions of crater for $2.0 \mathrm{~kg} \mathrm{C} 4$ explosion load.

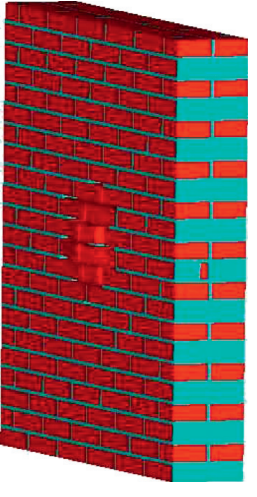

(a)

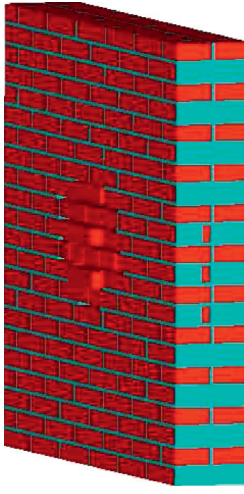

(b)

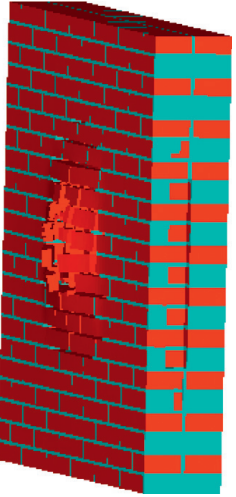

(c)

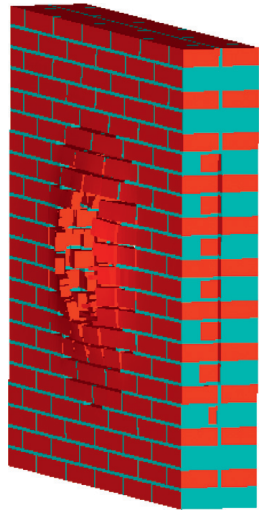

(d)

Figure 7: Destruction diagram of brick masonry under different explosive loads. (a) $0.5 \mathrm{~kg}$. (b) $1.0 \mathrm{~kg}$. (c) $2.0 \mathrm{~kg}$. (d) $4.0 \mathrm{~kg}$.

Compared with the simulation results in Figure 9, the experimental results are in good agreement with them.

Table 4 shows the dimensions of damage zones of brick masonry wall under different explosion loads. With the increase of the quantity of explosive, the lengths in $X$-direction and $Y$-direction increase. Moreover, the size of crater on front surface is smaller than that of fracture zone on back surface. When explosive is attached to brick masonry, released energy would be absorbed by masonry wall and thus compressive stress wave would spread in it. Once compressive stress wave reaches the back free surface, an enhanced tensile stress wave will appear due to impedance mismatch between wall and air. The reflected tensile wave from free surface encounters the inbound compressive stress resulting in total stress that is subtractive. When the total stress is tensile (tensile stress greater than inbound compressive stress) and exceeds the tensile strength of any point in the masonry matrix, cracks or fractures will occur. For brittle brick masonry material, the damage area on the back free surface can be larger than that on the front incident surface.

3.3. A Simple Predictive Model of the Dimensions of Hole. When the spherical explosive is detonated on the surface of masonry wall, according to the simulation and experiments, the crater hole is basically determined by the radius of the explosive. The simplified model can be described in Figure 10.

Since the explosion energy is released on the front surface of contact point and evenly in all directions, the radius of crater hole is merely controlled by the radius of explosive charge. However, the relationship between these two radii is not given clearly.

$$
r_{d} \propto r_{0} .
$$




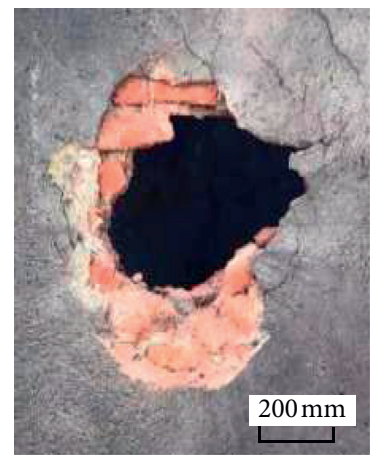

(a)

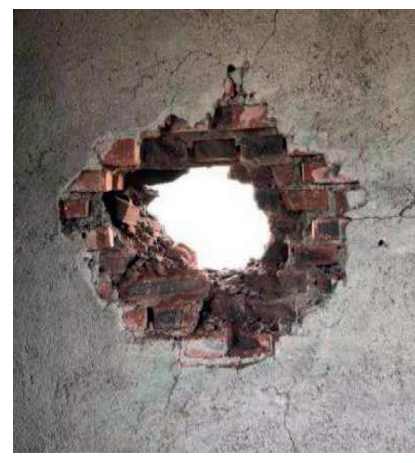

(b)

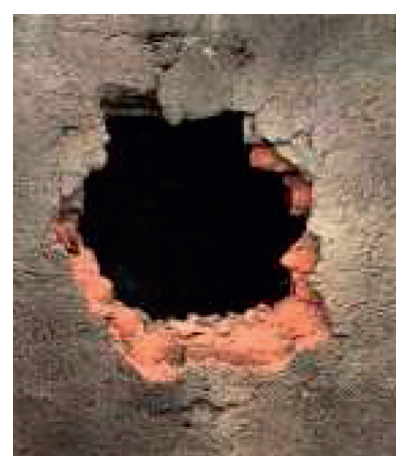

(c)

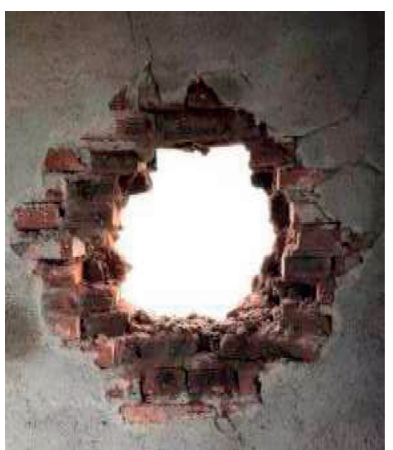

(d)

FiguRE 8: Experimental results under two different explosion loads. (a) Front view of $1.0 \mathrm{~kg}$. (b) Back view of $1.0 \mathrm{~kg}$. (c) Front view of $2.0 \mathrm{~kg}$. (d) Back view of $2.0 \mathrm{~kg}$.

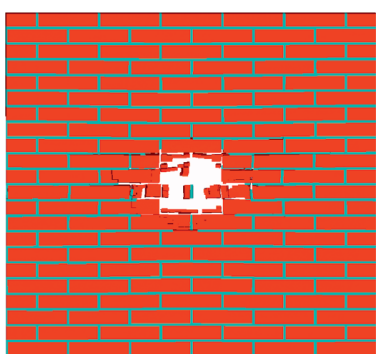

(a)

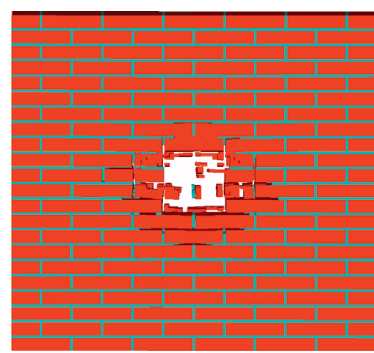

(b)

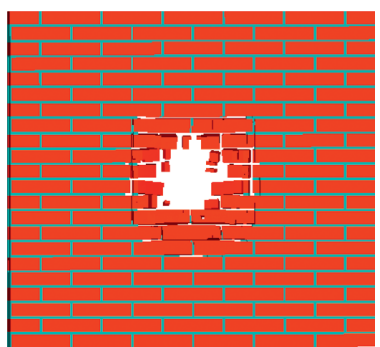

(c)

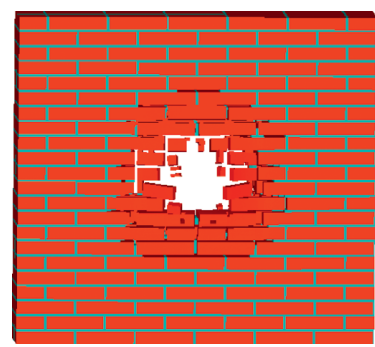

(d)

Figure 9: Simulation results under two different explosion loads. (a) Front view of $1.0 \mathrm{~kg}$. (b) Back view of $1.0 \mathrm{~kg}$. (c) Front view of $2.0 \mathrm{~kg}$. (d) Back view of $2.0 \mathrm{~kg}$.

TABLE 4: The damaged zones of brick masonry under different conditions.

\begin{tabular}{lccccc}
\hline \multirow{2}{*}{ Case no. } & \multirow{2}{*}{ Charge $(\mathrm{kg})$} & \multicolumn{2}{c}{ Crater in front surface } & \multicolumn{2}{c}{ Fracture in back surface } \\
& & $X$-direction $(\mathrm{mm})$ & $Y$-direction $(\mathrm{mm})$ & $X$-direction $(\mathrm{mm})$ & $Y$-direction $(\mathrm{mm})$ \\
\hline I & 0.5 & 266 & 252 & 366 & 338 \\
II & 1.0 & 364 & 347 & 524 & 4047 \\
III & 2.0 & 473 & 468 & 604 & 755 \\
IV & 4.0 & 637 & 630 & 618 \\
\hline
\end{tabular}

According to Table 4, the dimensions of front surface are drawn in Figure 11(a).

The ratios of radius of holes to the radius of explosive charges for four cases increase monotonously from 6.32 to 7.57. When fitting these data in Figure 11(b), it can be expressed as

$$
r_{d}=1.2859 r_{0}^{1.24306}
$$

Thus, a power function predicting model of the radius of hole is found.

\subsection{A Simple Fitting Model of Maximum Fragment Velocity.} With the increase in the quantity of the explosive, more and more cracks along the longitudinal direction are noticed. Once the hole is formed, the damaged bricks will be blown out to produce a number of fragments. Seen from the viewpoint of energy, the more quantity of explosive is used, the higher explosive energy loading on the surface of masonry wall is produced, and the higher the velocity of fragment gets. That is to say, the ejection velocities of fragments are determined by the radius of explosive too for spherical explosive charge. The fragment with maximum ejection velocity is found at the centre of crater or the apex of crater before breakup.

The maximum velocity of fragment $V_{\max }$ is proportional to the radius of spherical explosive:

$$
V_{\text {max }} \propto r_{0} .
$$

Figure 12 presents the maximum ejection velocity of fragments under different conditions. Adding coordinate point $(0,0)$, there are five groups of data. It is found that a power function curve fits these data well. 


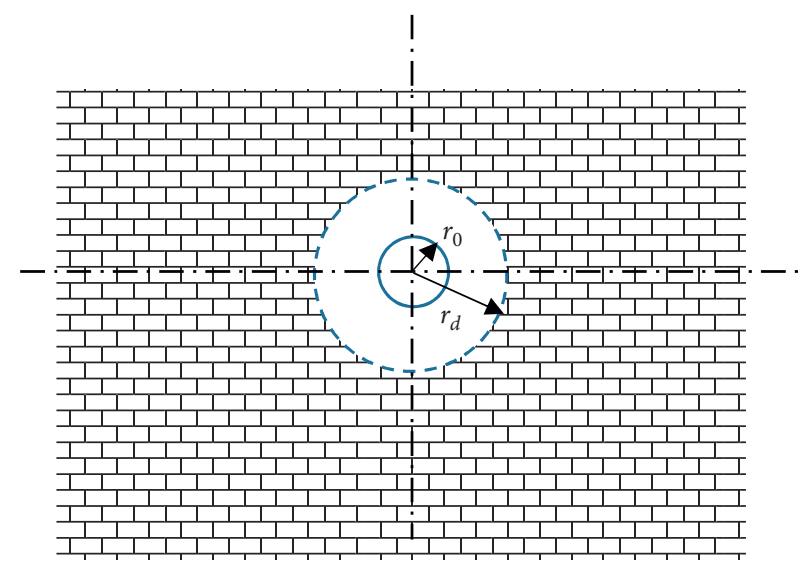

FIGURE 10: The relationship between the radius of crater hole and the radius of explosive.

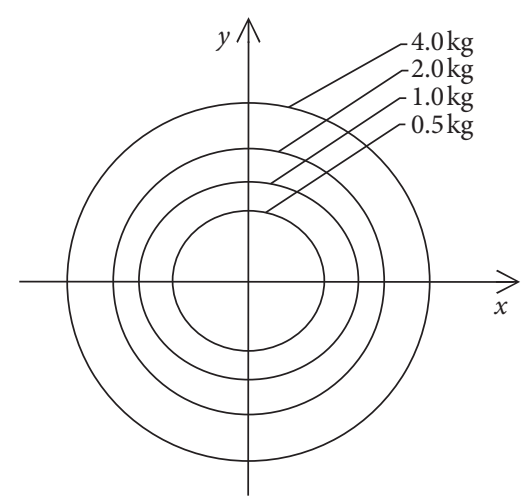

(a)

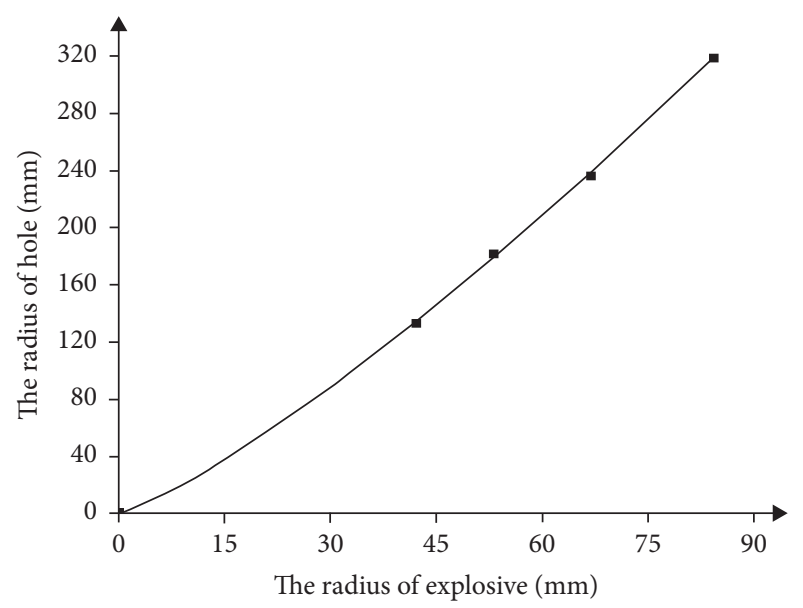

(b)

FIgURE 11: Crater on front surface under different charges. (a) Dimensions of holes. (b) Fitting curve.

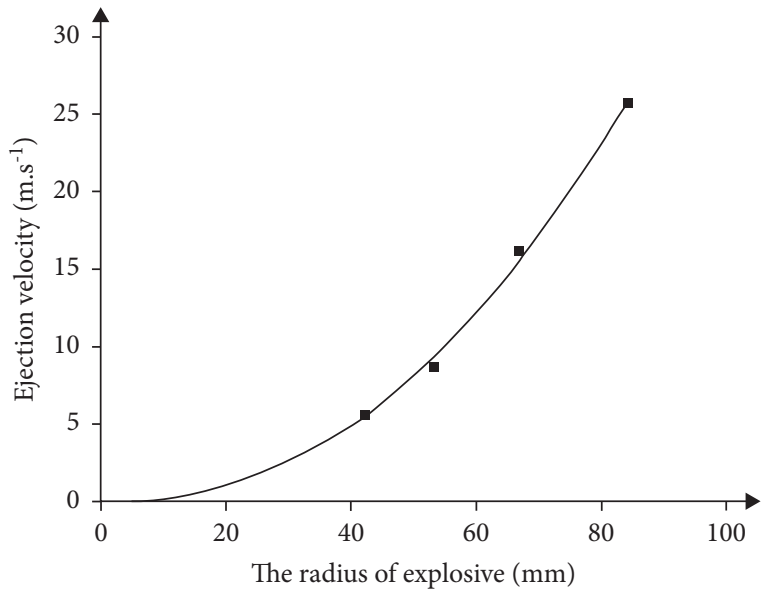

FIgURE 12: The maximum ejection velocities of fragments under different charges and fitting curve. 
Now, the maximum ejection velocity is power function to the radius of explosive.

$$
V_{\max }=0.00139 r_{0}^{2.21747}
$$

When the explosive is $4.0 \mathrm{~kg}$, the maximum ejection velocity can reach about $26 \mathrm{~m} / \mathrm{s}$, which may cause severe damage to surrounding equipment or personnel.

\section{Conclusions}

In this paper, numerical simulation and verification experiments of damage response of brick masonry under different amounts of $\mathrm{C} 4$ spherical charges are carried out. The following conclusions are obtained:

(1) When constrained brick masonry is exposed to contact explosion by spherical charge, a crater is formed on the front. The shape of cross section of crater is almost circular. The cross section dimension of crater increases monotonously with the radius of spherical explosive charge. For four cases in this study, the ratios of radial lengths to the radius of explosive charge increase from 6.32 to 7.57 .

(2) Explosion energy releases compressive wave directly on the front surface, and then stress wave (transmission wave) will travel to the back to make brickwork cracked. The combination effect of front compressive wave and back tensile wave are the main factors influencing the crack of brick masonry wall. When the back tensile wave is beyond the tensile strength of brick masonry, fracture zone will be pulled out to form a hole. The radius of hole is directly determined by the radius of the explosive. A power function predictive model is obtained to estimate the size of hole for C4 explosive detonated on the surface of $240 \mathrm{~mm}$ thickness masonry wall.

(3) The fragments can get higher velocities under larger explosion load, which may cause lethal damage to surrounding equipment or personnel. In the region of research, there is a power function relationship between maximum ejection velocity and the radius of explosive.

\section{Data Availability}

The data used to support the findings of this study are included within the article.

\section{Conflicts of Interest}

The authors declare that there are no conflicts of interest regarding the publication of this study.

\section{Acknowledgments}

The authors acknowledge the financial support for this work provided by the National Key R\&D Program of China (2017YFC0822105).

\section{References}

[1] F. Parisi, C. Balestrieri, and D. Asprone, "Blast resistance of tuff stone masonry walls," Engineering Structures, vol. 113, pp. 233-244, 2016.

[2] A. T. Edwards and T. D. Northwood, "Experimental studies of the effects of blasting on structures," The Engineer, vol. 30, pp. 538-546, 1960.

[3] C. W. Wong and M. Karamanoglu, "Modelling the response of masonry structures to gas explosions," Journal of Loss Prevention in the Process Industries, vol. 12, pp. 199-205, 1999.

[4] L. A. De Be' jar, L. Simmons, and J. L. Davis, "Standoff-mortar fragment velocity characterization before and after perforating conventional building walls," International Journal of Impact Engineering, vol. 35, pp. 1043-1052, 2008.

[5] P. W. Sielicki and T. Lodygowski, "Masonry wall behaviour under explosive loading," Engineering Failure Analysis, vol. 104, pp. 274-291, 2019.

[6] S. Shi, D. Du, W. Xu, and S. Wang, "Theoretical and experimental study on an innovative seismic retrofit solution for old brick masonry buildings," Engineering Structures, vol. 225, Article ID 111296, 2020.

[7] R. K. Varma, C. P. S. Tomar, S. Parkash, and V. S. Sethi, "Damage to brick masonry panel walls under high explosive detonations," Pressure Vessels and Piping Division ASME, vol. 351, pp. 207-216, 1997.

[8] B. Gabrielsen, C. Wilton, and K. Kaplan, "Response of arching walls and debris from interior walls caused by blast loading," Tech. Rep. AD-A014 957, URS Reasearch Company, San Mateo, CA, USA, 1975.

[9] J. S. Davidson, J. R. Porter, R. J. Dinan, L. H. Michael, and D. C. James, "Explosive testing of polymer retrofit masonry walls," Journal of Performance of Constructed Facilities, vol. 18, pp. 100-106, 2004.

[10] S. T. Dennis, J. T. Baylot, and S. C. Woodson, "Response of 1/4-scale concrete masonry unit (CMU) walls to blast," Journal of Engineering Mechanics, vol. 128, no. 2, pp. 134-142, 2002.

[11] S. Ahmad, A. Elahi, and H. Pervaiz, "Experimental study of masonry wall exposed to blast loading," Materiales De Construcción, vol. 64, no. 313, Article ID e007, 2014.

[12] R. A. Keys and S. K. Clubley, "Establishing a predictive method for blast induced masonry debris distribution using experimental and numerical methods," Engineering Failure Analysis, vol. 82, pp. 82-91, 2017.

[13] K. M. Norén-Cosgriff, N. Ramstad, A. Neby, and C. Madshus, "Building damage due to vibration from rock blasting," Soil Dynamics and Earthquake Engineering, vol. 138, no. 106331, pp. 1-13, 2020.

[14] X. Q. Zhou, H. Hao, and A. J. Deeks, "Numerical modeling of response and damage of masonry walls to blast loading," Transactions of Tianjin University, vol. 12, no. 1, pp. 132-137, 2006.

[15] R. Keys and S. Clubley, "Modeling debris distribution of masonry panels subject to blast loads using experimental \& applied element methods," in Proceedings of the 15th International Symposium on the Interaction of the Effects of $\mathrm{Mu}$ nitions with Structures, Potsdam, Germany, September 2013.

[16] M. Shadlou and M. M. Kashani, "A review on the current trends on computational modelling of masonry-infilled reinforced concrete frames," Journal of Physics Conference Series, vol. 1264, Article ID 012044, 2019.

[17] X. Wei and R. G. Stewart, "Model validation and parametric study on the blast response of unreinforced brick masonry 
walls," International Journal of Impact Engineering, vol. 37, pp. 1150-1159, 2010.

[18] C. S. Meyer, "Development of brick and mortar material parameters for numerical simulations," Dynamic Behavior of Materials, vol. 1, pp. 351-359, 2011.

[19] N. Gebbeken, T. Linse, and T. Araujo, "Masonry under dynamic actions - experimental investigations, material modeling and numerical investigations," Advances in Protective Structures Research, Taylor \& Francis Group London CRC Press, London, UK, pp. 131-162, 2012.

[20] L. Chen, Q. Fang, J. Fan, Y. Zhang, H. Hao, and J. Liu, "Responses of masonry infill walls retrofitted with CFRP, steel wire mesh and laminated bars to blast loadings," Advances in Structural Engineering, vol. 17, no. 6, pp. 817-836, 2014.

[21] S. Pietruszczak and X. Niu, "A mathematical description of macroscopic behavior of brick masonry," International Journal of Solids and Structures, vol. 29, pp. 531-546, 1992.

[22] G. Ma, H. Hao, and Y. Lu, "Homogenization of masonry using numerical simulations," Journal of Engineering Mechanics, vol. 127, no. 5, pp. 421-431, 2001.

[23] G. Milani, P. B. Lourenco, and A. Tralli, "Homogenized rigidplastic model for masonry walls subjected to impact," International Journal of Solids and Structures, vol. 46, no. 22-23, pp. 4133-4149, 2009.

[24] X. Wei and H. Hao, "Numerical derivation of homogenized dynamic masonry material properties with strain rate effects," International Journal of Impact Engineering, vol. 36, pp. 522-536, 2009.

[25] C. $\mathrm{Wu}$ and $\mathrm{H}$. Hao, "Derivation of 3D masonry properties using numerical homogenization technique," International Journal for Numerical Methods in Engineering, vol. 66, no. 11, pp. 1717-1737, 2010.

[26] C. Silva Luís, B. Lourenío Paulo, and M. Gabriele, "Rigid block and spring homogenized model (HRBSM) for masonry subjected to impact and blast loading," International Journal of Impact Engineering, vol. 109, pp. 14-28, 2017.

[27] B. Li, B. Chang, and L. Zhang, "Influence of charge density on JWL equation of state of explosives," Journal of Ordnance Equipment Engineering, vol. 42, no. 1, pp. 174-178, 2021.

[28] S. Koli, P. Chellapandi, L. B. Rao, and A. Sawant, "Study on JWL equation of state for the numerical simulation of nearfield and far-field effects in underwater explosion scenario," Engineering Science and Technology, an International Journal, vol. 23, pp. 758-768, 2020.

[29] L. Michael and N. Nikiforakis, "A multi-physics methodology for the simulation of the two-way interaction of reactive flow and elastoplastic structural response," Journal of Computational Physics, vol. 367, pp. 1-27, 2018.

[30] T. Borrvall and W. Riedel, "The RHT concrete model in LSDYNA," in Proceedings of the 8th European LS-DYNA Conference, Strasbourg, France, January 2011.

[31] C. Hecktter and J Sievers, "Comparison of the RHT concrete material model in LS-DYNA and ANSYS AUTODYN," in Proceedings of the 11th European LS-DYNA Conference, Salzburg, Austria, May 2017.

[32] J. F. Moxnes, G. Ødegårdstuen, A. Atwood, and P. Curran, "Mechanical properties of a porous material studied in a high speed piston driven compaction experiment," in Proceedings of the 30th International Annual Conference of the ICT, Frauenhofer ICT, Karlsruhe, Germany, June 1999.

[33] D. Ambrosini and B. Luccioni, "Effects of underground explosions on soil and structures," Underground Space, vol. 5, no. 4, pp. 324-338, 2019. 